\title{
Increased mortality and perioperative complications in patients with previous elective percutaneous coronary interventions undergoing coronary artery bypass surgery
}

\author{
Nikolaos Bonaros, MD, ${ }^{\mathrm{a}}$ Diana Hennerbichler, MD, ${ }^{\mathrm{a}}$ Guy Friedrich, MD, ${ }^{\mathrm{b}}$ Alfred Kocher, MD, ${ }^{\mathrm{a}}$ Otmar Pachinger, MD, ${ }^{\mathrm{b}}$ \\ Günther Laufer, MD, ${ }^{a}$ and Johannes Bonatti, MD $^{\mathrm{a}}$
}

\begin{abstract}
Objective: The relationship between previous percutaneous coronary intervention and perioperative outcome after coronary artery bypass grafting remains undetermined. The aim of the study was to investigate whether previous elective percutaneous coronary intervention influences the outcome of elective coronary artery bypass grafting.
\end{abstract}

\begin{abstract}
Methods: Between 2002 and 2007, 4412 consecutive patients underwent first-time open surgery at the Innsbruck Medical University. After excluding patients with a history of emergency percutaneous coronary intervention, we isolated 306 patients with elective percutaneous coronary intervention during the last 24 months before isolated coronary artery bypass grafting (group 1). Those patients were compared with 452 consecutive age-, gender-, and EuroSCORE-matched patients without a history of percutaneous coronary intervention (group 2), in terms of 30-day mortality, major adverse cardiac events, and perioperative complications.
\end{abstract}

Results: Both groups were comparable concerning preoperative linear EuroSCORE (group 1: $4.83 \pm 0.18$, group 2: $4.72 \pm 0.14, P=.63$ ). Patients who underwent previous elective percutaneous coronary intervention before coronary artery bypass grafting had an increase in perioperative mortality (group 1: $4.4 \%$ vs group 2: $2.4 \%$, $P<.001$ ) and major adverse cardiac events (group 1: $7.9 \%$ vs $4.3 \%, P<.001$ ). In addition, the incidence of bleeding complications (group 1: $5.9 \%$ vs group 2: $3.8 \%, P=.017$ ) and the number of blood products (group $1: 1.70 \pm 0.31$ vs $0.61 \pm 0.17, P<.001)$ used were higher in patients of group 1 . A higher incidence of acute renal failure $(5.9 \%$ vs $2.7 \%, P=.025)$ and renal replacement therapy $(3.6 \%$ vs $1.7 \%, P=.03)$ was observed in patients of group 1 .

Conclusion: Patients with a history of elective percutaneous coronary intervention before referral to coronary artery bypass grafting have a worse perioperative outcome in terms of mortality, major adverse cardiac events, and perioperative complications compared with patients without a history of percutaneous coronary intervention. This fact should be considered in risk stratification for patients who are scheduled for elective coronary artery bypass grafting.

The number of percutaneous coronary interventions (PCIs) has been continuously increasing during the last 15 years. ${ }^{1}$ PCI represents the main revascularization strategy in acute myocardial infarction, ${ }^{2}$ and cardiac interventionalists have gained significant experience with the interventional treatment of triple-vessel disease even in high-risk patients. ${ }^{3}$ However, despite several improvements in PCI technology there is increasing evidence proving the inferiority of midand long-term results after PCI compared with coronary artery bypass grafting $(\mathrm{CABG})$ even in the drug-eluting stent era. ${ }^{4,5} \mathrm{PCI}$, even if primarily successful, is associated with target lesion restenosis or target vessel restenosis mainly

From the Departments of Cardiac Surgery ${ }^{\mathrm{a}}$ and Cardiology, ${ }^{\mathrm{b}}$ Innsbruck Medical University, Innsbruck, Austria.

Received for publication March 8, 2008; revisions received July 20, 2008; accepted for publication Sept 16, 2008.

Address for reprints: Nikolaos Bonaros, MD, Department of Cardiac Surgery, Innsbruck Medical University, Anichstrasse 35, 6020, Innsbruck, Austria (E-mail: nikolaos.bonaros@i-med.ac.at).

J Thorac Cardiovasc Surg 2009; 137:846-52

$0022-5223 / \$ 36.00$

Copyright (c) 2009 by The American Association for Thoracic Surgery

doi: $10.1016 /$ j.jtcvs.2008.09.041 as the result of disease progression. ${ }^{6}$ For these reasons, approximately $10 \%$ to $20 \%$ of the patients with previous PCI are referred to CABG within 3 to 5 years after primary intervention. $^{7}$

Evidence accumulated from patients who underwent noncardiac surgery indicates that a history of PCI is associated with a higher incidence of perioperative adverse cardiac events. ${ }^{8,9}$ The outcome of CABG in patients with previous PCI still remains unexplored. Initial results demonstrated that previous PCI had no influence on perioperative outcome after CABG, provided that PCI was successful and no residual stenosis was left. ${ }^{10}$ A more detailed analysis including approximately 300 patients provided evidence that the perioperative outcome in patients with a history of repeat PCI who undergo CABG is significantly worse in terms of mortality and morbidity compared with patients with a history of a single PCI preoperatively. ${ }^{11}$ Because previous studies were designed to investigate multiple PCI before CABG and did not exclude acute interventions and cases with incomplete revascularization, the question whether the perioperative outcome after $\mathrm{CABG}$ is influenced by previous elective PCI remains unanswered. 

Abbreviations and Acronyms
$\mathrm{CABG}=$ coronary artery bypass grafting
IABP = intraaortic balloon pump
ICU = intensive care unit
MACE $=$ major adverse cardiac event
PCI = percutaneous coronary intervention

The aim of the present study was to investigate whether patients referred to CABG after previous elective PCI differ from patients without a history of PCI in terms of perioperative mortality and morbidity.

\section{MATERIALS AND METHODS \\ Patient Groups}

Between January 2002 and May 2007, 4412 consecutive patients underwent open surgery at the Innsbruck Medical University. All consecutive patients with a history of PCI who underwent primary isolated CABG (group $1, \mathrm{n}=306$ ) between January 2002 and May 2007 were retrospectively compared with an age-, gender-, and risk-adjusted cohort of patients without a history of PCI who underwent CABG during the same time frame (group $2, \mathrm{n}=452$ ). Patients with (1) an indication for cardiac operation other than isolated CABG (on an intent-to-treat basis), (2) cardiac reoperation, (3) a history of emergency or salvage PCI, (4) a time interval of PCI to CABG more than 24 months, (5) hybrid cases after PCI as a first act to a planned hybrid procedure, and (6) primary PCI failure were excluded from the analysis (Table 1). Risk adjustment was performed by means of predicted linear and logistic EuroSCORE risk stratification of the study group. Patients' age, gender, and linear EuroSCORE were used for matching between the groups.

\section{Data Collection}

Data used in the analysis were collected from the institutional database from the Department of Cardiac Surgery, Innsbruck Medical University, which was based on the data collected using the Data Collection form of the Society of Thoracic Surgeons (Adult Cardiac Surgery Database Data Collection form Version 2.25.1). Patients were followed by contacting the family practitioners or themselves directly.

\section{Study End Points}

The primary end points of the study ${ }^{12}$ included perioperative and 30-day mortality defined as the incidence of death episodes during hospitalization for surgery or up to 30 days after CABG.

The secondary end points included the following parameters of perioperative outcome:

- The use of blood products intraoperatively and postoperatively was defined as the number of red blood cells, fresh-frozen plasma, or platelet units used during and after the operation, respectively.

- Ventilation time was defined as the duration of ventilation needed postoperatively, including the potential need for additional ventilation after reintubation.

- Intensive care unit (ICU) stay was defined as the duration of ICU stay needed after the operation, including the potential need for additional ICU stay after readmission.

- Total length of stay was defined as the duration of postoperative stay at the Innsbruck Medical University, including stay at the ICU, intermediate care unit, and normal ward.

- Perioperative myocardial infarction was defined as the development of new persistent ST-segment, T- or Q-wave changes in electrocardiogram, new left bundle branch block, or troponin T elevation above the $5 \times 99$ th
TABLE 1. Patient groups

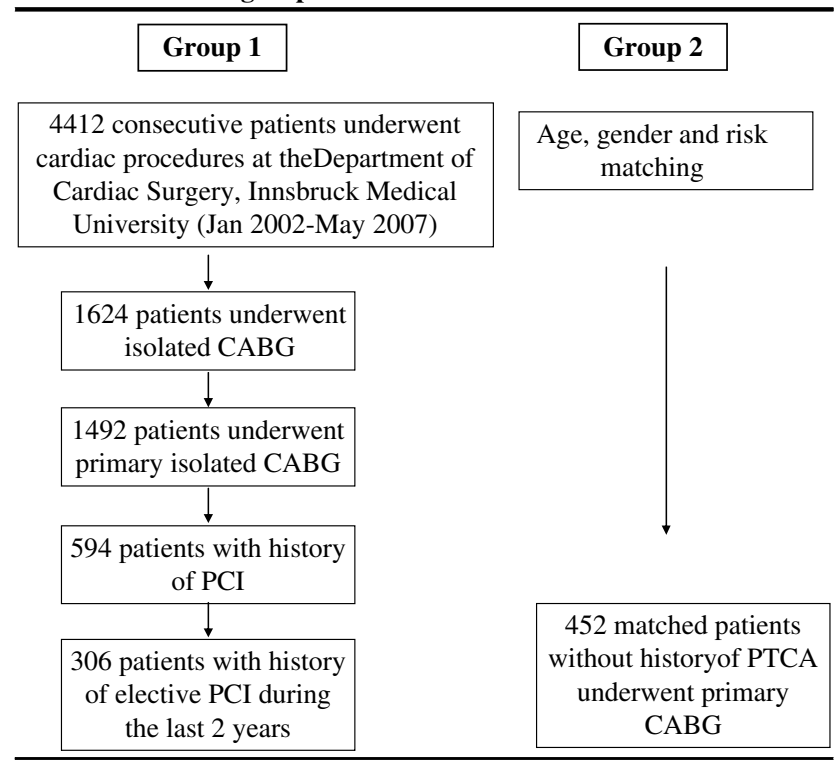

$C A B G$, Coronary artery bypass grafting; $P C I$, percutaneous coronary intervention $P T C A$, percutaneous coronary angioplasty.

percentile of the upper reference limit or creatinine kinase-MB/creatinine kinase ratio of greater than $10 \% .^{13}$

- Major adverse cardiac event (MACE) was defined as the combined end point of death, perioperative myocardial infarction, or need for repeat revascularization.

- Low cardiac output syndrome was presumed in patients with a cardiac index less than $2.2 \mathrm{~L} / \mathrm{min} / \mathrm{m}^{2}$ or a mean arterial pressure less than $60 \mathrm{~mm}$ $\mathrm{Hg}$, despite high-dose inotropic support (intravenously administered dopamine $>8 \mu \mathrm{g} / \mathrm{kg} / \mathrm{min}$, epinephrine $>0.1 \mu \mathrm{g} / \mathrm{kg} / \mathrm{min}$, or norepinephrine $>0.1 \mu \mathrm{g} / \mathrm{kg} / \mathrm{min})^{14}$

- Death was considered of cardiac origin if it was caused by perioperative myocardial infarction, significant cardiac arrhythmias, or refractory low cardiac output syndrome.

- Need for intraaortic balloon pump (IABP) was defined as any use of IABP after establishing cardiopulmonary bypass or at the postoperative phase.

- Postoperative atrial fibrillation was defined as any new episode of atrial fibrillation documented on online monitoring or electrocardiogram during the postoperative period.

- Postoperative renal failure was defined as any new onset of hemofiltration or dialysis or any increase in creatinine levels more than $0.5 \mathrm{mg} / \mathrm{dL}$ above the preoperative level. ${ }^{15}$

- Need for renal replacement therapy was defined as any incidence of new hemofiltration or dialysis postoperatively.

- Reoperation for bleeding was defined as any incidence of reoperation needed for bleeding complications.

- Initial ventilation time was defined as the duration of ventilation at the ICU (in case of need for reintubation, an additional ventilation time was calculated).

- In-hospital complications were defined as the combined end point of MACE, need for IABP, reintubation, readmission to the ICU, neurologic complications, renal failure, and need for renal replacement therapy or reoperation for bleeding during the postoperative phase and until discharge.

\section{Perioperative Management}

Platelet anti-aggregation agents were discontinued in all patients with the exception of patients with (1) left main stenosis, (2) unstable angina, or (3) 
prior implantation of bare mental stent up to 3 months preoperatively or prior implantation of drug-eluting stent up to 12 months preoperatively. Oral anticoagulation was converted to low molecular heparin at least 5 days before scheduled CABG. On-pump CABG was performed under full heparinization with $300 \mathrm{IU} / \mathrm{kg}$ heparin that was antagonized with protamine sulphate in a $1: 1$ relation; $2.6 \%$ of the PCI group and $2.9 \%$ of the non-PCI group underwent off-pump operation. Full-dose aprotinin was used intraoperatively in all patients studied. Standard cardiopulmonary bypass was used in most cases, and St Thomas II cold cardioplegia was used mixed with blood in a 4:1 relation. Dual aortic crossclamp was used in the majority of the patients, except for patients with significant atherosclerosis of the ascending aorta. Postoperative antiplatelet therapy included administration of salicylic acid intravenously during the first 24 hours after the operation combined with salicylic acid per os after extubation. Patients with contraindications to aspirin received clopidogrel as long-term anti-aggregation regimen.

\section{Statistical Analysis}

Categoric variables are presented as absolute numbers and frequencies in percentage and both groups were compared using the Pearson's chi-square test. Continuous variables were expressed as mean \pm standard deviation, and the groups were compared by means of $t$ test. Statistical analysis was performed using the Statistical Package for the Social Sciences 15.0 (SPSS Inc, Chicago, Ill). The authors had full access to the data and take responsibility for data integrity. All authors agreed to the content of the article as written.

\section{RESULTS \\ Patients' Demographics and Preoperative and Intraoperative Characteristics}

As shown in Table 2, no differences in the demographic data and preoperative characteristics were observed between the study groups, with the exception of history of myocardial infarction and use of platelet anti-aggregation. Both variables were observed more frequently in the PCI group. In addition, preoperative ejection fraction was significantly lower in this group (group 1: $46.4 \% \pm 11.9 \%$ vs group 2 : $54.7 \% \pm 14.3 \%, P<.001$ ), and approximately one third of the patients experienced myocardial infarction at the interval between PCI and CABG (Table 3). It is noteworthy that preoperative linear and logistic EuroSCORE levels were comparable between the 2 groups (linear EuroSCORE PCI group: $4.83 \pm 0.18$, non-PCI group: $4.72 \pm 0.14, P=$ $.63)$, because the control group was matched to group 1 in terms of age, gender, and EuroSCORE. Intraoperative data in terms of the use and duration of cardiopulmonary bypass, duration of aortic occlusion, total number of distal anastomosis, and use of arterial and venous grafts were also comparable between the 2 groups (Table 4 ).

\section{Mortality and Perioperative Outcome}

As shown in Figure 1, perioperative mortality was significantly higher in the PCI group (14/306) compared with the non-PCI group $(11 / 452,4.4 \%$ vs $2.4 \%, P<.001)$. Similarly, analysis of 30-day mortality revealed more than $70 \%$ increased mortality rates in the first group compared with the mortality rates of group $2(10 / 306,3.3 \%$ vs $8 /$ $452,1.8 \%, P<.001)$. Patients with prior PCI had a significantly worse perioperative outcome (linear perioperative outcome group 1: $1.44 \pm 0.26$ vs group 2: $0.53 \pm 0.18$,
TABLE 2. Preoperative characteristics of patients

\begin{tabular}{|c|c|c|c|}
\hline & $\begin{array}{c}\text { PCI } \\
(\mathbf{n}=\mathbf{3 0 6})\end{array}$ & $\begin{array}{c}\text { No PCI } \\
(n=452)\end{array}$ & $P$ value \\
\hline Age (y) & $64.6 \pm 10.0$ & $67.6 \pm 10.5$ & $P=.152$ \\
\hline Gender $(\mathrm{M} / \mathrm{F})$ & $230 / 74$ & $336 / 116$ & $P=.113$ \\
\hline \multicolumn{4}{|l|}{ Risk factors for CAD } \\
\hline History of smoking & $94(30.7 \%)$ & $139(30.8 \%)$ & $P=1.000$ \\
\hline Hyperlipidemia & $250(81.7 \%)$ & $370(81.9 \%)$ & $P=.373$ \\
\hline Hypertension & $238(77.7 \%)$ & $385(85.2 \%)$ & $P=.572$ \\
\hline Diabetes & $60(19.6 \%)$ & $112(24.8 \%)$ & $P=.112$ \\
\hline Family history of CAD & $53(17.3 \%)$ & $66(14.6 \%)$ & $P=.309$ \\
\hline Renal failure & $12(3.9 \%)$ & $36(8.0 \%)$ & $P=.132$ \\
\hline Dialysis & $8(2.6 \%)$ & $5(1.1 \%)$ & $P=.159$ \\
\hline Cerebrovascular accident & $12(3.9 \%)$ & $25(5.5 \%)$ & $P=.391$ \\
\hline Peripheral vascular disease & $46(15.0 \%)$ & $62(13.7 \%)$ & $P=.598$ \\
\hline Cerebrovascular disease & $27(8.8 \%)$ & $47(10.4 \%)$ & $P=.534$ \\
\hline \multicolumn{4}{|l|}{$\begin{array}{l}\text { Clinical manifestation } \\
\text { of CAD }\end{array}$} \\
\hline Myocardial infarction & $177(57.8 \%)$ & $170(37.6 \%)$ & $P<.001$ \\
\hline Congestive heart failure & $55(18.0 \%)$ & $64(14.2 \%)$ & $P=.155$ \\
\hline Stable angina & $158(51.6 \%)$ & $237(52.4 \%)$ & $P=.652$ \\
\hline Unstable angina & $75(24.5 \%)$ & $112(24.8 \%)$ & $P=.376$ \\
\hline Cardiogenic shock & $5(1.6 \%)$ & $4(0.9 \%)$ & $P=.242$ \\
\hline \multicolumn{4}{|l|}{ CV medication } \\
\hline Aspirin & $279(91.2 \%)$ & $416(92.0 \%)$ & $P=.425$ \\
\hline $\begin{array}{l}\text { Aspirin until } \\
\text { day of operation }\end{array}$ & $212(69.3 \%)$ & $187(41.4 \%)$ & $P<.001$ \\
\hline Clopidogrel & $63(20.6 \%)$ & $43(9.51 \%)$ & $P=.004$ \\
\hline Beta-blockers & $227(74.1 \%)$ & $312(69.0 \%)$ & $P=.276$ \\
\hline ACE antagonists & $161(52.6 \%)$ & $234(51.7 \%)$ & $P=.168$ \\
\hline Lipid lowering & $231(75.5 \%)$ & $326(72.1 \%)$ & $P=.427$ \\
\hline
\end{tabular}

$P C I$, Percutaneous coronary intervention; $C A D$, coronary artery disease; $C V$, cardiovascular; $A C E$, angiotensin-converting enzyme.

$P=.031$, logistic perioperative outcome group 1: $2.33 \pm$ 0.41 vs group 2: $1.26 \pm 0.39, P=.044)$. There was no difference between the groups in terms of linear and logistic predicted mortality (group 1: $4.8 \pm 3.1$ vs group 2: $4.7 \pm$ 3.0 for linear predicted mortality and group 1: $5.6 \pm 6.9$ vs group 2: $5.4 \pm 6.4$, for logistic predicted mortality).

\section{Perioperative Myocardial Infarction and MACE}

An approximately 4-fold increase in the incidence of perioperative myocardial infarction was observed in the PCI group, which was accompanied with significantly higher incidences of low cardiac output syndrome (Figure 2). Accordingly, the need for IABP support was 4 times higher in the first group. Analysis of the combined end point of MACE revealed an approximately 2-fold increase in the cohort of patients with prior PCI.

\section{Perioperative Need for Blood Products and Bleeding Complications}

As shown in Table 3, the need for blood transfusions, including red blood cells, fresh-frozen plasma, and platelet concentrates, during and after the operation was significantly 
TABLE 3. Preoperative angiographic characteristics and predicted mortality

\begin{tabular}{|c|c|c|c|}
\hline & PCI & No PCI & $P$ value \\
\hline \multicolumn{4}{|l|}{ No. of diseased vessels } \\
\hline 1 & $18(5.9 \%)$ & $27(6.0 \%)$ & $P=.352$ \\
\hline 2 & $45(14.7 \%)$ & $65(14.4 \%)$ & $P=.168$ \\
\hline 3 & $241(78.8 \%)$ & $360(79.6 \%)$ & $P=.427$ \\
\hline Left main stenosis & $61(19.9 \%)$ & $90(19.9 \%)$ & $P=.372$ \\
\hline $\begin{array}{l}\text { Previous PCI with } \\
\text { any stent }\end{array}$ & $298(97.4 \%)$ & $0(0 \%)$ & - \\
\hline $\begin{array}{l}\text { Previous PCI with } \\
\text { drug-eluting stent }\end{array}$ & $118(38.6 \%)$ & $0(0 \%)$ & - \\
\hline Number of stents/patient & 1.8 & $0(0 \%)$ & - \\
\hline $\begin{array}{l}\text { Need for target } \\
\text { lesion surgical } \\
\text { revascularization }\end{array}$ & $59(19.3 \%)$ & $0(0 \%)$ & - \\
\hline $\begin{array}{l}\text { Need for target } \\
\text { vessel surgical } \\
\text { revascularization }\end{array}$ & $136(44.4 \%)$ & $0(0 \%)$ & - \\
\hline $\begin{array}{l}\text { Myocardial infarction } \\
\text { during the last } 24 \text { mo }\end{array}$ & $101(33.0 \%)$ & $95(21 \%)$ & $P=.027$ \\
\hline Log predicted mortality & $5.6 \pm 6.9$ & $5.4 \pm 6.4$ & $P=.663$ \\
\hline Lin predicted mortality & $4.8 \pm 3.1$ & $4.7 \pm 3.0$ & $P=.633$ \\
\hline EF preoperatively & $46.4 \% \pm 11.9 \%$ & $54.7 \% \pm 14.3 \%$ & $P<.001$ \\
\hline $\begin{array}{l}\text { Pulmonary artery } \\
\text { mean pressure }(\mathrm{mm} \mathrm{Hg})\end{array}$ & $21.9 \pm 6.3$ & $22.3 \pm 8.1$ & $P=.547$ \\
\hline
\end{tabular}

higher in the PCI group. Accordingly, approximately 4 times more patients in the PCI group underwent reoperation for bleeding complications.

\section{Perioperative Renal Failure and Need for New Dialysis}

The incidence of perioperative renal failure was significantly higher in the study group. Twice as many patients of this group required new renal replacement therapy during the postoperative period.

\section{Other Parameters Influencing Outcome}

There was no difference noted between the 2 groups in terms of ventilation time and ICU stay (Table 4). The total postoperative length of stay, neurologic events, and incidence of postoperative atrial fibrillation were also comparable between the 2 study arms. However, analysis of the cumulative end point in-hospital complications revealed a significantly worse outcome in the PCI group compared with patients without a history of PCI $(43.2 \%$ vs $19.4 \%$ respectively, $P<.001)$. Diabetic patients have been included in a separate analysis, which yielded similar results as demonstrated for the whole patient population (Table 5).

\section{DISCUSSION}

We performed a retrospective analysis of 4412 consecutive patients in terms of the outcome of surgical coronary re-
TABLE 4. Perioperative data

\begin{tabular}{|c|c|c|c|}
\hline & $\begin{array}{c}\text { PCI } \\
(n=306)\end{array}$ & $\begin{array}{c}\text { No PCI } \\
(n=452)\end{array}$ & $P$ value \\
\hline istal anastomoses (arteries) & $1.24 \pm 0.71$ & $1.21 \pm 0.69$ & $P=.511$ \\
\hline Distal anastomoses (veins) & $1.69 \pm 1.05$ & $1.59 \pm 1.11$ & $P=.296$ \\
\hline CPB time (min) & $120 \pm 58$ & $124 \pm 67$ & $P=.361$ \\
\hline Crossclamp time (min) & $66 \pm 35$ & $73 \pm 40$ & $P=.129$ \\
\hline OPCAB & $8(2.6 \%)$ & $13(2.9 \%)$ & $P=.754$ \\
\hline Intraoperative blood products & $1.70 \pm 0.31$ & $0.61 \pm 0.17$ & $P<.001$ \\
\hline Red blood cell units & $1.03 \pm 0.21$ & $0.42 \pm 0.11$ & $P<.001$ \\
\hline Fresh-f & $0.58 \pm 0$ & $0.18 \pm$ & $P=.003$ \\
\hline Platelet units & $0.12 \pm 0.02$ & $0.07 \pm 0.01$ & $P=.015$ \\
\hline Red blood ce & $0.90 \pm 0.31$ & $0.34 \pm 0.11$ & $P=.036$ \\
\hline Fresh-frozen plasma units ICU & $0.62 \pm 0.16$ & $0.37 \pm 0.09$ & $P=.041$ \\
\hline Platelet $\mathrm{L}$ & $0.10 \pm 0.02$ & $0.08 \pm 0.01$ & $P=.074$ \\
\hline Initial ven & $26.5 \pm 118.3$ & $26.9 \pm 86.1$ & $P=.960$ \\
\hline Addition: & $14.7 \pm 110.7$ & $7.0 \pm 46.0$ & $P=.055$ \\
\hline Total ventilation time (h) & $71.1 \pm 351.9$ & $36.9 \pm 114.8$ & $P=.027$ \\
\hline Initial ICU stay (h) & $69.9 \pm 164.5$ & $61.3 \pm 123.3$ & $P=.43$ \\
\hline Additional ICU stay (h) & $211.0 \pm 373.4$ & $197.2 \pm 158.2$ & $P=.913$ \\
\hline Total ICU stay (h) & $76.8 \pm 182.4$ & $70.0 \pm 143.9$ & $P=.583$ \\
\hline Length of stay (d) & $13.5 \pm 7.5$ & $11.8 \pm 7.1$ & $P=.264$ \\
\hline Readmission to ICU (\%) & $14(4.6 \%)$ & $14(3.1 \%)$ & $P=.062$ \\
\hline Low cardiac output syndrome & $18(5.9 \%)$ & $15(3.3 \%)$ & $P=.025$ \\
\hline IABP perioperatively (\%) & $16(5.2 \%)$ & $8(1.8 \%)$ & $P=.002$ \\
\hline Reoperation for bleeding ( $\%)$ & $18(5.9 \%$ & $17(3.8 \%)$ & $P=.022$ \\
\hline Stroke $(\%)$ & $6(1.9 \%)$ & $8(1.7 \%)$ & $P=.216$ \\
\hline $\begin{array}{c}\text { Postoperative atrial } \\
\text { fibrillation }(\%)\end{array}$ & $98(32 \%)$ & & $P=.319$ \\
\hline
\end{tabular}

$\overline{P C I}$, Percutaneous coronary intervention; $C P B$, cardiopulmonary bypass; $O P C A B$, off-pump coronary artery bypass; $I C U$, intensive care unit; $I A B P$, intraaortic balloon pump.

vascularization in patients with and without a history of PCI. To minimize bias, only patients with isolated coronary artery disease who had not undergone any previous cardiac surgical procedure were eligible to the analysis. To achieve comparable patient populations in the 2 study groups, all patients with a history of PCI to CABG interval more than 24 months were considered to be exposed to coronary artery disease for a longer period; therefore, they were excluded from the study. Our results demonstrate that patients with prior PCI who undergo CABG have higher mortality and periprocedural complication rates, which thus far is not predicted by currently available preoperative risk assessment scores.

The current study demonstrated that both 30-day mortality and overall mortality were approximately 2 times higher in patients with a history of PCI. This finding is consistent with the results of Thielmann and colleagues, ${ }^{16}$ who reported a 3 times higher incidence of perioperative mortality after CABG in diabetic patients with triple-vessel disease and a history of multiple PCI. The worse outcome after CABG in the PCI group can be explained by several factors: First, although the calculated EuroSCORE of these patients is comparable to that of the control group, a higher incidence 


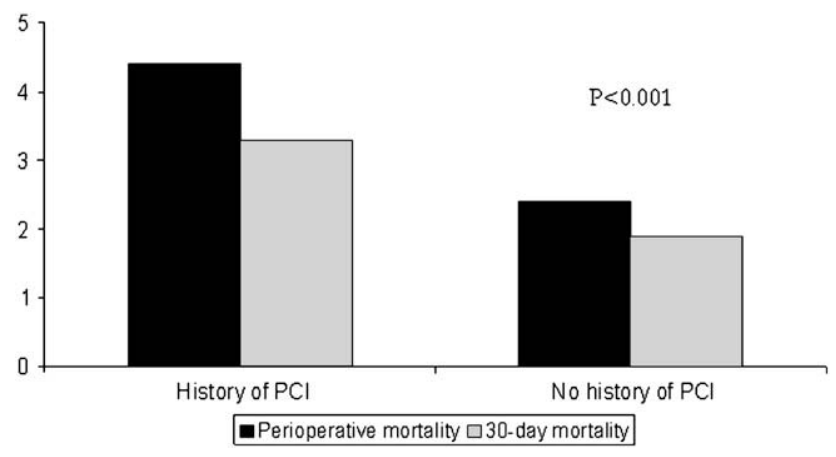

FIGURE 1. Perioperative and 30-mortality rates in patients with and without history of PCI after CABG. PCI, Percutaneous coronary intervention.

of myocardial infarction history has been noted in the PCI group. The higher numbers of myocardial infarction both before and after PCI suggest an aggressive form of coronary artery disease that could be related to the existence of unstable or ruptured coronary plaques. The lower baseline ejection fraction in the study group can be attributed to the loss of contractile elements after myocardial infarction, approximately one third of which took place during the interval between PCI and CABG. The higher incidence of intraoperative myocardial infarction, low output syndrome, and the need for IABP perioperatively suggest that the increased perioperative risk may be associated with preexisting

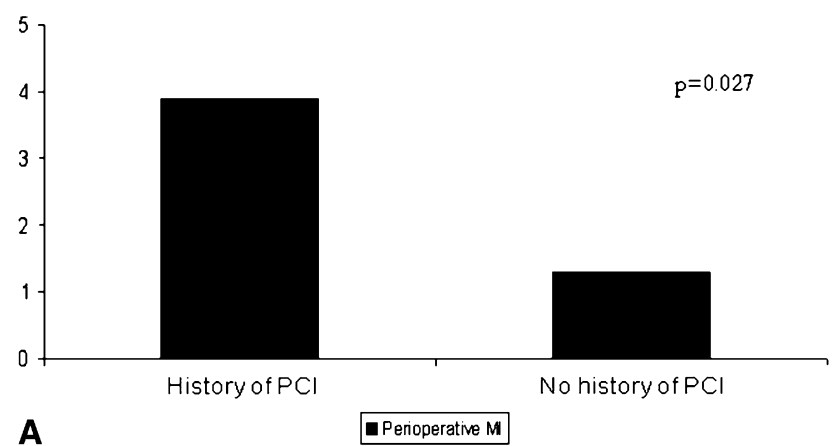

A

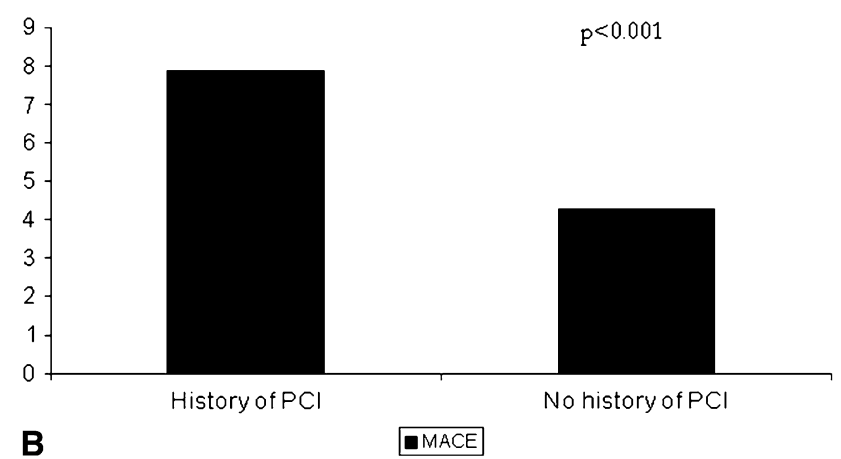

FIGURE 2. Incidence of (A) perioperative myocardial infarction and (B) MACE in patients with and without history of PCI who underwent CABG. $P C I$, Percutaneous coronary intervention; $M I$, myocardial infarction; $M A C E$, major adverse cardiac event.
TABLE 5. Perioperative mortality and outcome in diabetic patients with and without history of percutaneous coronary intervention after coronary artery bypass grafting

\begin{tabular}{lccc}
\hline & $\begin{array}{c}\text { PCI } \\
(\mathbf{n}=\mathbf{6 0})\end{array}$ & $\begin{array}{c}\text { No PCI } \\
(\mathbf{n}=\mathbf{1 1 2})\end{array}$ & $\boldsymbol{P}$ value \\
\hline Preoperative ejection fraction & $42 \pm 12$ & $51 \pm 16$ & $P=.004$ \\
Total ventilation time (h) & $86 \pm 134$ & $60 \pm 160$ & $P=.084$ \\
Total ICU stay (h) & $134 \pm 304$ & $102 \pm 218$ & $P=.355$ \\
Length of stay (d) & $14.3 \pm 6.2$ & $12.8 \pm 7.4$ & $P=.413$ \\
Low cardiac output syndrome & $4(6.7 \%)$ & $4(3.6 \%)$ & $P=.031$ \\
IABP perioperatively (\%) & $7(11.7 \%)$ & $10(8.9 \%)$ & $P=.034$ \\
Reoperation for bleeding (\%) & $6(10 \%)$ & $5(4.4 \%)$ & $P=.021$ \\
Stroke (\%) & $1(1.7 \%)$ & $1(0.9 \%)$ & $P=.580$ \\
Perioperative mortality (\%) & $3(5 \%)$ & $2(1.8 \%)$ & $P=.013$ \\
30-d mortality (\%) & $2(3.3 \%)$ & $2(1.8 \%)$ & $P=.034$ \\
Perioperative myocardial & $5(8.3 \%)$ & $2(1.8 \%)$ & $P=.002$ \\
$\quad$ infarction (\%) & & & \\
MACE (\%) & $6(10 \%)$ & $4(3.6 \%)$ & $P=.003$ \\
Renal failure (\%) & $5(8.3 \%)$ & $6(5.4 \%)$ & $P=.027$ \\
Dialysis (\%) & $4(6.7 \%)$ & $4(3.6 \%)$ & $P=.015$ \\
In-hospital complications (\%) & $28(47 \%)$ & $31(28 \%)$ & $P=.023$ \\
\hline$P C I$, Percutaneous coronary intervention $; I C U$, intensive care unit; IABP, intraaortic \\
balloon pump; $M A C E$, major adverse cardiac event. & & \\
& & &
\end{tabular}

PCI-induced myocardial damage or perioperative stent thrombosis even in patients without a history of myocardial infarction. Incidental minor side-branch occlusion has been postulated to aggravate periprocedural myocardial injury, especially in complex type $\mathrm{C}$ stenoses requiring multiple stenting or use of long stents, and has been reported to occur in $11 \%$ of patients after PCI. ${ }^{17,18}$ Lesions with a high burden of plaque have been associated with an increased risk of myocardial necrosis in the distal area as a result of distal microembolization. ${ }^{19,20}$ Thielmann and colleagues ${ }^{16}$ have reported an even worse outcome of diabetic patients with a history of PCI who undergo coronary revascularization surgery. High mortality and MACE rates of approximately $8 \%$ and $14 \%$, respectively, demonstrate that diabetic patients have a significant disadvantage with regard to the long-term outcome after primary PCI.

Another important finding of our study was that preoperative risk assessment using EuroSCORE did not predict perioperative outcome. Although both patient groups were matched in terms of age, gender, and EuroSCORE-mediated risk stratification, the perioperative outcome was significantly worse in the PCI group. This is attributed to the fact that EuroSCORE does not take into consideration previous $\mathrm{PCI}$ in calculating risk of cardiac surgery. None of the available risk analysis models include previous PCI in risk stratification for CABG. ${ }^{21}$ In the Society of Thoracic Surgeons database, risk analysis for previous PCI is included in the data acquisition; however, it has no influence on the risk stratification model. ${ }^{22}$ On the other hand, almost all models used for preoperative stratification, including EuroSCORE, take into consideration preoperative ejection fraction and 
history of myocardial infarction, both of which were more frequently seen in the PCI group. Higher incidence of preoperative myocardial infarction may be associated with more aggressive disease, incomplete revascularization at primary $\mathrm{PCI},{ }^{23}$ or stent therapy failure, including stent thrombosis. ${ }^{24}$

Our study demonstrated a higher incidence of bleeding complications, including reoperations for bleeding and perioperative use of blood products in patients with a history of PCI. A closer look at patients' preoperative characteristics reveals that patients in the PCI group were more often receiving platelet anti-aggregation therapy; the mean interval from PCI to CABG was approximately 9 months. Data from on- and off-pump coronary surgery suggest that clopidogrel or aspirin premedication in CABG is an independent predictive factor for increased bleeding complications and reoperation for bleeding. ${ }^{25,26}$ Noteworthy antiplatelet medication was discontinued in all patients included in our series except for patients with high-risk coronary anatomy or history of PCI with bare metal or drug-eluting stent(s) for a maximum of 6 or 12 months, respectively, according to the guidelines of the American Heart Association and the American College of Cardiology. ${ }^{27}$

The higher incidence of renal complication detected in the PCI group was not surprising, given the higher incidence of reoperation for bleeding and the higher incidence of perioperative low output syndrome in the PCI group. Hypovolemic shock and acute heart failure are 2 independent risk factors for the development of acute renal failure in patients with preoperatively normal renal function mostly due to prerenal cause. $^{28}$

\section{Study Limitations}

Although this study was designed to avoid patient selection bias, it is still based on a retrospective analysis, which may make publication bias inevitable. Repeat PCI is an independent risk factor for perioperative mortality and morbidity in elective CABG. Although we included data from repeat PCIs, we did not perform a separate statistical analysis because this topic has been addressed in a previous study. ${ }^{11}$ Repeat PCI in patients may help to identify a specific highrisk population within the PCI group with an aggressive form of coronary artery disease. The retrospective design of the study and the inclusion of only a relatively low number of patients from a single center should be considered as study limitations. However, our strict exclusion criteria allowed us to concentrate on a homogenous population of patients with new onset of coronary artery disease. The difference in preoperative ejection fraction between the 2 groups is not expected to bias the results because it accounts for only 1 point of the calculated linear EuroSCORE risk.

\section{CONCLUSIONS}

The study results demonstrated that a positive history of PCI had a significantly negative effect on the perioperative out- come after CABG. Higher mortality rates were observed, and these patients had a higher risk for myocardial, renal, and bleeding complications, which may also have a negative impact on the long-term results. Our results provide evidence that higher perioperative mortality is associated with both myocardial dysfunction and bleeding complications. Preoperative risk evaluation using EuroSCORE did not predict the actual perioperative outcome, because previous PCI intervention is not taken into consideration as the most effective risk-stratification tool. Our study may have a significant impact on the treatment of coronary artery disease as it provides evidence that some current practice strategies, such as incomplete revascularization or procrastination of surgical revascularization, lead to a significantly worse perioperative outcome.

\section{References}

1. Rosamond W, Flegal K, Friday G, et al, for the American Heart Association Statistics Committee and Stroke Statistics Subcommittee. Heart Disease and Stroke Statistics-2007 Update. A Report From the American Heart Association Statistics Committee and Stroke Statistics Subcommittee. Circulation. 2007;115: e69-171.

2. Anderson JL, Adams CD, Antman EM, et al. American College of Cardiology; American Heart Association Task Force on Practice Guidelines (Writing Committee to Revise the 2002 Guidelines for the Management of Patients With Unstable Angina/Non-ST-Elevation Myocardial Infarction); American College of Emergency Physicians; Society for Cardiovascular Angiography and Interventions; Society of Thoracic Surgeons; American Association of Cardiovascular and Pulmonary Rehabilitation; Society for Academic Emergency Medicine. ACC/AHA 2007 guidelines for the management of patients with unstable angina/non-ST-Elevation myocardial infarction: a report of the American College of Cardiology/ American Heart Association Task Force on Practice Guidelines (Writing Committee to Revise the 2002 Guidelines for the Management of Patients With Unstable Angina/Non-ST-Elevation Myocardial Infarction) developed in collaboration with the American College of Emergency Physicians, the Society for Cardiovascular Angiography and Interventions, and the Society of Thoracic Surgeons endorsed by the American Association of Cardiovascular and Pulmonary Rehabilitation and the Society for Academic Emergency Medicine. J Am Coll Cardiol. 2007;50:e1-157.

3. Mehran R, Dangas GD, Kobayashi Y, et al. Short- and long-term results after multivessel stenting in diabetic patients. J Am Coll Cardiol. 2004;43:1348-54.

4. Hannan EL, Racz MJ, Walford G, et al. Long-term outcomes of coronary-artery bypass grafting versus stent implantation. N Engl J Med. 2005;352:2174-83.

5. Javaid A, Steinberg DH, Buch AN, et al. Outcomes of coronary artery bypass grafting versus percutaneous coronary intervention with drug-eluting stents for patients with multivessel coronary artery disease. Circulation. 2007;16(11 Suppl): I200-6.

6. Alderman EL, Kip KE, Whitlow PL, et al. Bypass Angioplasty Revascularization Investigation. Native coronary artery disease progression exceeds failed revascularization as cause of angina after five years in the bypass angioplasty revascularization investigation (BARI). J Am Coll Cardiol. 2004;44:766-74.

7. Serruys PW, Ong AT, van Herwerden LA, et al. Five-year outcomes after coronary stenting versus bypass surgery for the treatment of multivessel disease: the final analysis of the Arterial Revascularization Therapies Study (ARTS) randomized trial. J Am Coll Cardiol. 2005;46:575-81.

8. Wilson SH, Fasseas P, Orford JL, et al. Clinical outcome of patients undergoing non-cardiac surgery in the two months following coronary stenting. J Am Coll Cardiol. 2003;42:234-40

9. Van Norman GA, Posner K. Coronary stenting or percutaneous transluminal coronary angioplasty prior to noncardiac surgery increases adverse perioperative cardiac events: the evidence is mounting. J Am Coll Cardiol. 2000;36:2351-2.

10. Van den Brule JM, Noyez L, Verheugt FW. Risk of coronary surgery for hospita and early morbidity and mortality after initially successful percutaneous intervention. Interact Cardiovasc Thorac Surg. 2005;4:96-100.

11. Thielmann M, Leyh R, Massoudy P, et al. Prognostic significance of multiple previous coronary interventions in patients undergoing elective coronary artery bypass surgery. Circulation. 2006;114(Suppl 1):I441-7. 
12. Shanian DM, Blackstone EH, Edwards FH, et al. STS Workforce on evidence based surgery. Cardiac surgery risk models: a position article. Report from the STS workforce on evidence-based surgery. Ann Thorac Surg. 2004;78:1868-77.

13. Thygesen K, Alpert JS, White HD, et al. Universal definition of myocardial infarction. Circulation. 2007;116:2634-53.

14. Rao V, Ivanov J, Weisel RD, Ikonomidis JS, Christakis GT, David TE. Predictors of low cardiac output syndrome after coronary artery bypass. J Thorac Cardiovasc Surg. 1996;112:38-51.

15. Mora-Mangano C, Diamondstone LS, Ramsay JG, et al. Renal dysfunction after myocardial revascularization: risk factors, adverse outcomes, and hospital resource utilization - the Multicenter Study of Perioperative Ischemia Research Group. Ann Intern Med. 1998;128:194-203.

16. Thielmann M, Neuhauser M, Knipp S, et al. Prognostic impact of previous percutaneous coronary intervention in patients with diabetes mellitus and triple-vessel disease undergoing coronary artery bypass surgery. J Thorac Cardiovasc Surg. 2007; 134:470-6.

17. Javaid A, Buch AN, Steinberg DH, et al. Does creatinine kinase-MB (CK-MB) isoenzyme elevation following percutaneous coronary intervention with drugeluting stents impact late clinical outcome? Catheter Cardiovasc Interv. 2007; 70:826-31

18. Dibra A, Mehilli J, Braun S, et al. Inflammatory response after intervention assessed by serial C-reactive protein measurements correlates with restenosis in patients treated with coronary stenting. Am Heart J. 2005;150:344-50.

19. Porto I, Selvanayagam JB, Van Gaal WJ, et al. Plaque volume and occurrence and location of periprocedural myocardial necrosis after percutaneous coronary intervention. Circulation. 2006;114:662-9.

20. Selvanayagam JB, Cheng AS, Jerosch-Herold M, et al. Effect of distal embolization on myocardial perfusion reserve after percutaneous coronary intervention: a quantitative magnetic resonance perfusion study. Circulation. 2007;116: 1458-64.

21. Nilsson J, Algotsson L, Höglund P, Lührs C, Brandt J. Comparison of 19 pre-operative risk stratification models in open-heart surgery. Eur Heart J. 2006;27: 867-74.

22. Edwards FH, Clark RE, Schwartz M. Coronary artery bypass grafting the Society of Thoracic Surgeons National Database experience. Ann Thorac Surg. 1994;57: 1245-9.

23. Kalarus Z, Lenarczyk R, Kowalczyk J, et al. Importance of incomplete revascularization in patients with acute myocardial infarction treated with percutaneous coronary intervention. Am J Cardiol. 2007;153:304-12.

24. Kornowski R, Mehran R, Satler LF, et al. Procedural results and late clinical outcome following multivessel coronary stenting. J Am Coll Cardiol. 1999;33:42-6.

25. Kapetanakis EI, Medlam DA, Petro KR, et al. Effect of clopidogrel premedication in off-pump cardiac surgery: are we forfeiting the benefits of reduced hemorrhagic sequelae? Circulation. 2006;113:1667-74.

26. Karthik S, Grayson AD, McCarron EE, et al. Reexploration for bleeding after coronary artery bypass surgery: risk factors, outcomes, and the effect of time delay. Ann Thorac Surg. 2004;78:527-34.

27. Grines CL, Bonow RO, Casey DE Jr, et al. Prevention of premature discontinuation of dual antiplatelet therapy in patients with coronary artery stents: a science advisory from the American Heart Association, American College of Cardiology, Society for Cardiovascular Angiography and Interventions; American College of Surgeons, and American Dental Association, with representation from the American College of Physicians. Circulation. 2007;115:734-9.

28. Doddakula K, Al-Sarraf N, Gately K, et al. Predictors of acute renal failure requiring renal replacement therapy post cardiac surgery in patients with preoperatively normal renal function. Interact Cardiovasc Thorac Surg. 2007;6:314-8. 